\title{
Leibniz on the existence of atoms
}

\author{
Ricardo Mena \\ UNAM - Instituto de Investigaciones Filosóficas \\ Circuito Maestro Mario de la Cueva s/ $n$ Mexico City 04100 \\ Mexico \\ ricardo.mena21@gmail.com
}

Article info

CDD: 193

Received: 05.06.2017; Accepted: 14.06.2017

DOI: http://dx.doi.org/10.1590/0100-6045.2017.V40N2.RM

Keywords

Leibniz

History of Philosophy

Metaphysics

\begin{abstract}
In this paper I present and evaluate Leibniz's two main arguments against the existence of atoms. In this context atoms are extended particles that are absolutely hard, homogeneous, indivisible, and indestructible by natural means. As we shall see, Leibniz's arguments are flawed in a very instructive way. The first argument is in tension with the claim that God created the best possible world. The second argument overgeneralizes in an undesirable way. However, as I shall discuss in the last section of the paper, even if the arguments are somehow defective, at least the first one contributes valuable insights to contemporary metaphysics.
\end{abstract}

\section{Atoms}

An extended object is an object that is extended in space. For instance, a mountain is an extended object whereas a geometrical point is not. If one thinks that there are extended objects, it is fairly easy to find examples of objects that can be divided. An apple is an extended object, and it's a common practice to cut apples in half. Apples are clear cases of extended objects that can be divided. Usually, extended objects can be divided more than once; we can cut an apple in many pieces. Moreover, if we had a proper knife, we could spend the whole evening dividing an

Manuscrito - Rev. Int. Fil. Campinas, v. 40, n. 2, pp. 19-38, abr.jun. 2017. 
apple in smaller and smaller pieces. Thus, if we are ready to accept the existence of extended objects, it is easy to accept the existence of divisible objects.

A further question is whether extended objects can be divided an infinite number of times. This question is far from trivial. For practical reasons we cannot divide an object an infinite number of times. Since every time we divide an object we require some time to do so, dividing an object an infinite number of times would require an eternity. But we also know that if we cannot divide an object an infinite number of times, it does not follow that the object cannot be so divided. Perhaps an immortal could spend forever dividing an extended object. Perhaps she could get the division process started and find out that at some point that the object cannot be divided any further. This issue is far from easy to decide.

Call Atomism the view according to which there are extended particles that are absolutely hard, homogeneous, indivisible, and indestructible by natural means. An atom is an object that satisfies these conditions. Atomism is motivated by two separate claims. (1) The claim that there are a number of different levels of fundamentality-intuitively, the chemical level is more fundamental than the biological level. ${ }^{1}$ And (2), the claim that there is a fundamental level-perhaps we can think of that level as containing all and only the most basic physical particles. The idea behind (1) is that objects of a less fundamental level are build up form objects of a more fundamental level. The idea behind (2) is that there are extended objects that are the building blocks of every extended object and that they cannot be built out of any other object-these objects inhabit the fundamental level. Thus, Atomism holds that atoms inhabit the fundamental level and that everything-except for atoms-is built out of atoms.

\subsection{Atoms Misconceived}

I would like to introduce a further remark for the purposes of clarification. It is easy to mistakenly identify Atomism with the view that

${ }^{1}$ This, however, can be contested (Schaffer, 2010).

Manuscrito - Rev. Int. Fil. Campinas, v. 40, n. 2, pp. 19-38, abr.-jun. 2017. 
there are extended simples. 2 An extended simple is an object that has a spatial dimension and lacks proper parts. It is not hard to understand the motives behind such identification. One may reason in the following way: an object can be divided if and only if it has parts. For example, an apple has a right part and a left part (among many other) and for that reason it can be divided into at least two parts. Then, an object is an extended simple if and only if it is extended and cannot be divided-if it were divisible, it would have parts, and then it would not be a simple object. 3 Therefore, atoms are extended simples.

This, I take it, is not a particularly good argument. We should not grant that easily that if an object can be divided, then it has proper parts. A reason for this may be that the existence of mereological simples is not out of the question. The view that persons are mereological simples is defensible, however it is clear that even if persons are mereological simples, they can be divided.

Furthermore, the following claim is false: if an object has proper parts, then it can be divided. There is nothing incoherent about the view according to which there is an extended object, with proper parts, that cannot be divided. Think of an extended object: a sphere, if you like. One can be ready to distinguish parts within this sphere. The right part and the left part of the sphere are obvious candidates. However, there is nothing wrong with imagining that the material constitution of the sphere is such that its parts cannot be discontinuous - there is no way in which the sphere can be divided. This sphere, let's suppose, would be completely annihilated before being divided. If an object like this is possible (and it seems like it is), then it is false that something has parts if and only if it is divisible. 4

${ }^{2}$ For a defense of the existence of extended simples see McDaniel (2007).

${ }^{3}$ Leibniz, in The Monadology, claims that if something lacks parts then it cannot be divided. Here is the passage: "But where there are no parts, neither extension, nor shape, nor divisibility is possible." (p.213) Perhaps Leibniz made this claim because he did not consider the possibility of extended atoms. Now we know that this is a possibility that should be seriously considered.

${ }^{4}$ Compare with Shaffer(2003).

Manuscrito - Rev. Int. Fil. Campinas, v. 40, n. 2, pp. 19-38, abr.jun. 2017. 
From the above we shouldn't conclude that atoms should be conceived as extended objects with proper parts. It is mistaken to characterize atoms as extended simples for two reasons. First, because the interesting properties of atoms are independent of whether or not they extended simples. Second, because whether or not they are extended simples is irrelevant to the relation between divisibility and fundamentality. Thus, it is better to characterize atoms as indivisible particles and not as extended simples.

One may think it's worrisome to leave open the possibility of atoms having proper parts. This is so, one may think, because proper parts are objects that, together with other objects, compose a further entity. It may seem at first that if this is so, then atoms cannot be fundamental particles. The reason being that if there are objects that compose atoms, those objects have better credentials to be fundamental particles, since the existence of a composite object depends on the existence of its parts.

Here is one story I am tempted to tell in favor of the view that atoms can have proper parts and be fundamental objects. Suppose atoms have proper parts. Now, since atoms are fundamental objects, the existence of anything different from an atom depends on the existence of atoms. Hence, the existence of the proper parts of an atom depends on the existence of atoms. If this is so, then we can keep the view that atoms are fundamental entities with proper parts.

The idea supporting this view is that the proper parts of an atom are not separate entities. It is not as if the proper parts of atoms are a bunch of particles that come together to compose an atom. In the same vein, it is not as if the proper parts of an atom have properties independently of the atoms they are part of. According to this picture, if the proper parts of an atom have some interesting properties. They acquire those properties from the whole they are part of. Then, according to this view, the properties of everything there is-including the proper parts of atoms-supervene on the properties of atoms. If this is so, there is nothing wrong in saying that atoms are fundamental particles and that they have proper parts.

Manuscrito - Rev. Int. Fil. Campinas, v. 40, n. 2, pp. 19-38, abr.-jun. 2017. 


\section{Leibniz's Arguments against the Existence of Atoms}

In what follows I will present and evaluate what I take to be the most interesting arguments against the existence of atoms in Leibniz's writings. The arguments that Leibniz presents are scattered through a number or writings and vary in both plausibility and clarity. Moreover, the same arguments are often presented differently in some of his writings. Of course, this complicates interpretation. However in some cases, his reasons for rejecting atoms remain constant.

I will start by citing the passage that got me interested in Leibniz's views on the existence of atoms. The passage is from New Essays on Human Understanding and goes as follows:

...if there were atoms, i.e. perfectly hard and perfectly unalterable bodies which were incapable of internal change and could differ from one another only in size and in shape, it is obvious that since they could have the same size and shape they would then be indistinguishable in themselves and discernible only by means of external denominations with no internal foundation; which is contrary to the greatest principles of reason. (p.231)

The point of this passage is this: from the supposition that atoms exist we can derive some consequences that conflict with "the greatest principles of reason", and for that reason atoms cannot exist. This is an extremely interesting idea. The point is that there are some principles of reason, and on the basis of these principles we can derive conclusions regarding the metaphysical structure of reality.

Let me explain. If Leibniz is right, then it follows from the principles of reason that there are no atoms. If this is so, we can draw the conclusion (given some plausible assumptions) that whatever occupies the fundamental level of reality cannot have all the properties attributed to atoms. Furthermore, as we shall see, from one of "the greatest principles of reason" Leibniz concludes that every extended object is divisible-contrary to the supposition that atoms exist. Thus, Leibniz claims that from reason alone we can conclude that infinite divisibility of any extended object.

Manuscrito - Rev. Int. Fil. Campinas, v. 40, n. 2, pp. 19-38, abr.jun. 2017. 


\subsection{The Greatest Principles of Reason}

There is good textual evidence to the effect that Leibniz already had in mind the greatest Principles of Reason in his 1686 paper "Primary Truths." The reasons for this are the following: In "Primary Truths" Leibniz presents a number of general principles that he used several times in arguing in favor of some view or other. When Leibniz appeals to these principles he treats them as undeniable truths that must be taken into account. Another reason to think that what we find in "Primary Truths" are the greatest principles of reason is that he uses the principles mentioned there to argue against the existence of atoms. I think it is not coincidence that in New Essays on Human Understanding Leibniz claims that the existence of atoms contradicts the greatest principles of reason and that in "Primary Truths" he states some principles that are used to prove that atoms do not exist. In what follows I will present the principles presented in "Primary Truths."

Here's the opening paragraph of "Primary Truths":

The primary truths are those which assert the same thing of itself or deny the opposite of its opposite. For example, " $\mathrm{A}$ is $\mathrm{A}$," " $\mathrm{A}$ is not not A," or "if it is true that A is B, then it is false that A is not b or that A is not B." Also "everything is as it is," "everything is similar or equal to itself," "nothing is greater or less than itself," and others of this sort. Although they themselves may have their degrees of priority, nonetheless they can all be included under the name 'identities.' (p.31)

On the basis of this paragraph we can notice that Leibniz has a wide conception of what can be called an 'identity.' Today philosophers would be tempted to say that identity statements are those of the form "A is B" and that all the other examples provided by Leibniz in the paragraph above are not identity statements but consequences of identity statements plus other axioms and definitions. However, this is just a point regarding terminology.

Right after the paragraph just quoted Leibniz makes a remarkable claim. He says that "all remaining truths are deduced to primary truths with the help of definitions." Notice that the claim is not that other 
logical or analytic truths are deducible from what he calls 'identities.' Rather, the claim is that all the truths-universal, particular, necessary, and contingent truths - are deducible from identities.5 Although this view is highly controversial, I will go on as if it were not. I am prepared to do this since a great deal of interesting results follow from it.

The first interesting result that follows from Leibniz's view on true propositions is that in a true proposition the predicate is always contained in the subject. The idea is that the concept (or notion) of the subject can be expressed as a list of properties and, then, a predicate is contained in the subject only if it is one of the members of the list. The rationale supporting this conclusion goes as follows: if a true proposition can be reduced to an identity statement, then the proposition is true only in virtue of the notions that are contained in the subject. This is so, the story goes, since identity statements hold only in virtue of the notions that are contained in the subject. Thus, if a statement follows from an identity statement-plus some definitions-it cannot contain information that is not contained in the subject. Thus, the reasoning goes, in every true statement the predicate has to be contained in the subject-otherwise it could not be derived from an (identity) statement that holds only in virtue of the notions contained in the subject.

The above principle is far from innocent, since a substantial and counterintuitive principle follows from it. The derived principle is this: "that there are no purely extrinsic denominations, denominations which have absolutely no foundation in the very thing denominated." 6 A purely extrinsic denomination (or extrinsic property) is one that an object cannot have if it were alone in the world. In other words, it is a property that an object has depending on its relation to another object.

Let us see how this principle follows from Leibniz's views on true propositions. Assume that there are purely extrinsic denominations.

5 Compare: Russell (1971).

${ }^{6}$ For the purpose of clarity I am changing Leibniz's order of exposition. In "Primary Truths" Leibniz first proves his Law of identity and then he shows that there are no purely extrinsic denominations. I think that the prove of the Law of Identity is better understood once we have a grasp of the proof that there are no purely extrinsic denominations.

Manuscrito - Rev. Int. Fil. Campinas, v. 40, n. 2, pp. 19-38, abr.jun. 2017. 
Then one of those denominations can be predicated truthfully of some object. If so, there is a true proposition in which a purely extrinsic denomination is predicated of a subject. Hence, there is a true proposition in which the predicate is not contained in the subject. But this contradicts the principle according to which in a true proposition the predicate is always contained in the subject. Therefore, there are no purely extrinsic denominations.

From the principle that every true proposition is deducible from identity statements plus definitions it follows the Principle of Sufficient Reason-as we shall see, this is the main principle in Leibniz's arguments against the existence of atoms. According to this principle "nothing is without a reason." In other words, if something is the case, then there is a reason why it is the case. Leibniz argues in favor of this principle as follows:

"Otherwise there would be a truth $[\ldots]$ which could not be resolved into identities, contrary to the nature of truth, which is always an explicit or implicit identity.” (p.31)

Let me explain. If $A$ is deduced from $B$, then $A$ counts as a reason for B. To put it in other words, when one deduces A from B, one establishes the truth of $A$ on the basis of the truth of B. Now, if a true statement $A$ can be deduced from an identity statement $\mathrm{B}$, we say that the reason why $\mathrm{A}$ is true is that $\mathrm{B}$ is true. And since every true statement is deducible from an identity statement, it follows that everything has a reason-the assumption is, of course, that if something is a reason for the truth of $\mathrm{A}$, it is a reason for $\mathrm{A}$.

Moreover, Leibniz's principle of identity of indiscernibles can be proven from the principles above. Leibniz states the law as follows: "in nature, there cannot be two individual things that differ in number alone." The idea is that if $a$ is different from $b$, then there is a property possessed by one of them and not by the other. If there were no such property, $a$ and $b$ would differ in number alone, contrary to what the principle says.

The proof of this law from the considerations above is quite interesting. Assume that $a$ is different from $b$ and that they differ in number alone. Since $a$ and $b$ differ in number alone, they have exactly the same internal notions. Thus, $a$ cannot be differentiated from $b$ on the

Manuscrito - Rev. Int. Fil. Campinas, v. 40, n. 2, pp. 19-38, abr.-jun. 2017. 
basis of its extrinsic notions. Furthermore, it has been shown that there are no extrinsic denominations. Then, $a$ cannot be distinguished from $b$ on the basis of its extrinsic denominations, since there are none. If $a$ and $b$ cannot be differentiated on the basis of their intrinsic or extrinsic denominations, they cannot be differentiated at all. Not even God--if such an entity exists--could differentiate $a$ from $b$, since there is no basis for doing so. Therefore, $a$ cannot be different from $b$ since there is nothing that differentiates them. ${ }^{7}$

From all this it follows that the identity conditions for any given object have to be purely internal. This follows trivially from the rejection of the existence of extrinsic denominations. Since the identity conditions of objects have to appeal to their properties, and since there are no extrinsic denominations, those conditions have to appeal only to intrinsic denominations. From this follows Leibniz's Law of Identity-the idea that no two objects differ in number alone. Although it is interesting to see how this follows from Leibniz's principles, it is worth noting that one can have independent reasons accept that law. The argument goes as follows: for every object $\mathrm{x}$, there is a possible world $w$ in which $\mathrm{x}$ is the only inhabitant. In $w, \mathrm{x}$ has identity conditions. Since in $w$ there is nothing but $\mathrm{x}$, the identity conditions of $\mathrm{x}$ must be purely intrinsic. Furthermore, the identity conditions of any object do not vary across possible worlds. Therefore, the identity conditions of any given $\mathrm{x}$ are purely intrinsic. ${ }^{8}$

2.2 Leibniz's arguments against the existence of atoms

7 Other principles follow from Leibniz's view on true propositions. However, those principles, although very interesting, are not directly relevant for the purpose of this paper. For that reason I will only mention them. One of them is the principle according to which the "perfect notion of an individual substance contains all of its predicates, past, present, and future. Another one is the view that "[e]very individual substance contains in its perfect notion the entire universe" and that "all individual created substances are different expressions of the same universe." Lastly, the view that "assuming the distinction between soul and body, from this we can explain their union without the common hypothesis of an influx.... and without the hypothesis of an occasional cause which appeals to a Deus ex machina."

8 This argument can be found in Cover. J.A. and Hawthorne. J. (1999).

Manuscrito - Rev. Int. Fil. Campinas, v. 40, n. 2, pp. 19-38, abr.jun. 2017. 
To the best of my knowledge, Leibniz has two arguments against the existence of atoms that are based in the principles presented in the last section. I will begin by presenting the weaker one. Then I will present the stronger one. In the last section I will discuss both of them. As we shall see, this discussion brings out some interesting issues regarding the metaphysics of material objects. This is so even if the outcome of the discussion is the rejection of Leibniz's arguments.

The first argument can be found in Leibniz's fourth letter to Clark. The argument is based on The Principle of Sufficient Reason. This is how the argument goes: It is reasonable to suppose that at least some objects can be divided. Let us pick any of these objects. Now we ask: "what reason can anyone assign for confining nature in the progression of subdivision?" (p.332). The point of the question is this: since a given object can be divided, if there is some point at which the division has to stop-as the atomist says there is-there must be a reason why the division stops at that particular point and not at a different one. It is fairly clear that The Principle of Sufficient Reason has been invoked: if there is at point at which an object cannot be further divided, there must be a reason why all divisions have to stop at that particular point. It seemsthe argument continues - that there is no reason why the division has to stop at some point or another. If we could claim that divisibility stops at some particular point, we could also claim that divisibility stops at a different point. If this is so, there is no reason why the division stops at some specific point, and given The Principle of Sufficient Reason, there is no reason why the division stops at all. Therefore, there are no indivisible particles. There are no atoms.

Here is the core idea in this argument: if there is no reason for $p$, then $\sim p$. Leibniz holds that there is no reason why the divisibility of objects should stop at some level. From this he concludes that it is not the case that the divisibility of objects stops at some level. But if there are atoms, then the divisibility of objects stops at some level--the atomic level. Therefore, Leibniz concludes, there are no atoms.

Now let's consider the second argument against the existence of atoms. For this purpose we should go back to the first Leibniz quotation in this paper. Let's consider the quotation in its full form:

Manuscrito - Rev. Int. Fil. Campinas, v. 40, n. 2, pp. 19-38, abr.-jun. 2017. 
If two individuals were perfectly similar and equal and, in short, indistinguishable in themselves, there would be no principle of individuation. I would even venture to say that in such a case there would be no individual distinctness, no separate individuals. That is why the notion of atoms is chimerical and arises only from men's incomplete conceptions. For if there were atoms, i.e. perfectly hard and perfectly unalterable bodies which were incapable of internal change and could differ from one another only in size and in shape, it is obvious that since they could have the same size and shape they would then be indistinguishable in themselves and discernible only by means of external denominations with no internal foundation; which is contrary to the greatest principles of reason. (p.231)

It's fairly clear how Leibniz uses "the greatest principles of reason" in this argument. The two principles that he uses in his argument are, first, the one according to which there are no purely extrinsic denominations and, second, the one according to which if two objects are not identical, there must be an intrinsic denomination had by one but not the other.

The idea then, is that if there are atoms, it could be the case that there are two atoms, $a$ and $b$, of exactly the same shape and size. Since atoms are perfectly hard and homogenous particles, $a$ and $b$ would not differ internally at all. But since there are no purely extrinsic denominations, there is no basis to differentiate $a$ form $b$. Therefore, $a$ and $b$ are identical. ${ }^{9}$ Furthermore, in a possible world in which all the atoms are of

${ }^{9}$ Leibniz argues in a similar way in his 1703 letter to Volder:

“....as things are commonly conceived, bodies can't even be distinguished modally. For, if you take two bodies, A and B, equal and with the same shape and motion, it will follow from such a notion of body, namely one derived from the putative modes of extension alone, that they have nothing by which they can be distinguished intrinsically. Is it therefore the case that A and B are not different individuals?...This and innumerable other things of this sort indicate that the true notions of things are completely turned on their heads by the new philosophy which forms substances form what is only material and passive." (p.174)

Manuscrito - Rev. Int. Fil. Campinas, v. 40, n. 2, pp. 19-38, abr.jun. 2017. 
the same shape and size, we would be forced to say that there is only one atom. These consequences are completely unacceptable. Thus, there are no atoms.

It's important to keep in mind that these arguments against the existence of atoms are not intended as arguments in favor of the impossibility of atoms. The only thing that Leibniz was trying to prove with these arguments is that in the actual world there are no atoms, as opposed to the stronger claim that there is no possible world in which atoms exist. Here is a relevant passage that supports this interpretation:

When I deny that there are two drops of water perfectly alike, or any two other bodies indiscernible from each other, I don't say it is absolutely impossible to suppose them, but that it is a thing contrary to the divine wisdom, and which consequently does not exist. 10

Thus, even if it's possible that atoms exist, they do not exist because their existence contradicts God's wisdom.

Interestingly enough, there is some tension between the previous quote and the passage from the New Essays on Human Understanding considered above. In the passage from the New Essays Leibniz says that in case there is no intrinsic difference between two objects "I would even venture to say that in such a case there would be no individual distinctness, no separate individuals." I take this to imply that if there is no intrinsic difference between two objects, there is in fact just one object. This claim is the expected one given that he argued in Primary Truths that, if we accept certain assumptions, the identity conditions of individuals only apply to intrinsic denominations. However, in the quotation of the previous paragraph Leibniz says that it's possible that two different objects exist even though they share all their intrinsic denominations. Since the view presented in the New Essays is implied by what he calls "the greatest principles of reason" and the view presented in the last quotation is inconsistent with those principles, I give more weight to what is said in the New Essays. This may be a reason to think

${ }^{10}$ Leibniz, "Leibniz's Fifth Paper", in Philosophical Essays, (p.333)

Manuscrito - Rev. Int. Fil. Campinas, v. 40, n. 2, pp. 19-38, abr.-jun. 2017. 
that Leibniz is committed to the view that atoms are impossible objects.

\section{Critical remarks on Leibniz's arguments}

In what follows I will cast some doubt on Leibniz's arguments against the existence of atoms. After doing so I will reflect on the insights that a contemporary metaphysics can draw from Leibniz's arguments and from my critical remarks. Let's start with a criticism of the first argument against the existence of atoms. The strategy is to show that, given Leibniz's commitment to the claim that God created the best of possible worlds, he cannot hold that there is no reason why the divisibility of a given object should stop at some point.

Let's start by considering the claim that God created the best possible world. Leibniz's reasons to hold this view are the following:

Nor can I approve the opinion of some moderns who maintain boldly that what God has made is not of the highest perfection and that he could have done much better. For it seems to me that the consequences of this opinion are wholly contrary to the glory of God: as a lesser evil is relatively good, so a lesser good is relatively evil. And to act with less perfection than one could have is to act imperfectly.

His point is fairly clear. If this is not the best possible world, God's creation is imperfect. But that cannot be, so this must be the best of all possible worlds. Of course, this reasoning can be challenged. One could reason in a similar way and conclude that God does not exist. The argument would proceed as follows: since it is very clear that this is not the best of possible worlds, and God could only have created the best of possible worlds, God does not exist. This argument resembles quite a bit the Problem of Evil argument against the existence of God.

For the sake of the argument let's accept Leibniz's principles discussed above and that God created the best of all possible worlds. Now, let's consider the following claim: all things being equal, if possible worlds $\mathrm{w}$ and w' are exactly alike except because $\mathrm{w}$ is more complex at its fundamental level than w', then w' is more perfect than w.

Manuscrito - Rev. Int. Fil. Campinas, v. 40, n. 2, pp. 19-38, abr.jun. 2017. 
By w's fundamental level I mean the mereological level containing w's basic building blocks. Of course, here I am talking about the most fundamental physical level - the most basic physical particles are good candidates to be at the fundamental level of our world. 11 Thus, if $\mathrm{w}$ and w' only differ at the fundamental level, if some event happens in one of the worlds, it also happens at the second-it is just that the event in $\mathrm{w}$ has a more complex fundamental structure. The intuitive justification for this claim that w' is more perfect than w is this: w' has the same type of events as $\mathrm{w}$, but it requires a simpler fundamental level to support them, and then there is some unnecessary complexity at w. If simplicity is a perfection, then it is clear that w' is more perfect than w. In what follows I shall use these claims to show that Leibniz's argument in favor of the infinite divisibility of extended object can be blocked-so long as we assume, along with Leibniz, that God created the best of all possible worlds.

Here is the argument: assume there is an atomic level-a level such that the objects at that level are indivisible atoms. Now we can argue that there are reasons for the existence of some level at which the atom level should be: there is one level at which the divisibility of objects stops. Now accept, as Leibniz does, that God created the best of all possible worlds (our world). Accept as a working hypothesis that there is an infinite series of possible worlds where the atomic level of the first world in the series is at the highest level and as we move through the series, the atomic level goes one level down-that is to say, the fundamental physical structure runs deeper and becomes more complex.12 Thus, the first member of the series only contains scattered atoms and whatever meaningless mereological sums we can build with them. Let's assume that the atoms in that world are quite boring and nothing complex can

11 Perhaps Leibniz would think that the monads are the most fundamental entities. I don't know whether the question of divisibility even makes sense when monads are under consideration. For this reason it is important to restrict the arguments to the physical world.

${ }^{12}$ Thus, in the first world of the series the largest objects are atoms. As we move through the series the complexity of each object in the world will increase, since the fundamental level goes down one level for each place in the series.

Manuscrito - Rev. Int. Fil. Campinas, v. 40, n. 2, pp. 19-38, abr.-jun. 2017. 
be built with them. As we move down the series we find worlds with more and more complex objects that require a more complex fundamental physical structure. Also, as we move down the series we find worlds with complex objects that can be divided a larger number of times, compared to objects in worlds closer to the first member of the series - the limit is imposed by the atom level at that world.

We say that the number that corresponds to the atomic level of the first world in the series is 0 , and the number that corresponds to the atomic level of the next world in the series is 1, and so on. (Intuitively, our world would get assigned a large number. Think of all the large objects there are, and how many parts they have before we can reach their most fundamental physical parts - a person has many parts, composed of many other parts, which eventually are composed of cells, then molecules, then other particles, and so on.) Furthermore, assume that for each $n$ and $n-1$ in the series $n$ duplicates $n-1$ as far as possible. So according to this picture $n$ would be as perfect as $n-1$ from the $\mathrm{n}-1$ level up. So the more complex worlds duplicate as much as possible the less complex ones - the relevant difference is that one of these worlds is more complex at its fundamental level. Of course, the difference between very distant members of this series will be quite significant. What matters is that the worlds that are close to each other in the series resemble each other quite a bit.

Now choose an arbitrary $\mathrm{m}$ such that $\mathrm{m}$ is the number corresponding to the atomic level of one of the worlds in the series. Consider the following reasoning: if the possible world in the series that has atomic level $m+1$ is such that it is more perfect than the possible world with atomic level $\mathrm{m}$, then if we move from $\mathrm{m}$ to $\mathrm{m}+1$ we will be closer to the actual world (since the actual world is the most perfect world in the series). If this is so, it is because the world with atom level $\mathrm{m}$ does not have enough complexity in its fundamental level to generate all the perfections that the most perfect possible world must have. Notice that if God created the best of all possible worlds, there has to be a world in the series with atomic level $\mathrm{m}+1$ such that it is the most perfect in the series - the assumption here is, of course, that the world with atomic level 0 cannot be the best of all possible worlds, and this is, presumably, a safe assumption. If it were the case that for any world with atom level

Manuscrito - Rev. Int. Fil. Campinas, v. 40, n. 2, pp. 19-38, abr.jun. 2017. 
$\mathrm{n}$ there is a world with atom level $\mathrm{n}+1$ that is more perfect, then, since the series is infinite, there would not be a world that is the most perfect-contrary to the supposition that God created the best possible world. Similarly, if there is a possible world with atomic level $m-1$ such that it is more perfect than the world with atomic level $\mathrm{m}$, then if we move from $m$ to $m-1$ we will be closer to the actual world. The idea in this case is that if there is such a world, then the world with atomic level $m$ will be less perfect than the world with atomic level $m-1$ in so far as it adds unnecessary complexity at the fundamental level.

Following this reasoning we could figure out, at least in principle, what the atomic level of the actual world is (provided that we know enough fundamental physics to do it). The idea is that if the actual world is the best possible world, then there will be an atomic level with number $\mathrm{n}$ such that the world with atomic level $\mathrm{n}+1$ will be less perfect because it adds unnecessary complexity at the fundamental level, and the world with atom level $n-1$ will be less perfect because it won't have the necessary resources to build the best of all possible worlds. Therefore, the atom level corresponding to the actual world is exactly the number $\mathrm{n}$ that satisfies those constraints.

What this shows is that if we combine atomism with the view that God created the best of all possible worlds, we have a way of escaping Leibniz's first argument against the existence of atoms. Recall that a crucial component of Leibniz's argument is that if we suppose that atomism is true, there is no reason why the divisibility of objects should stop at some particular level. From this-based on the principle of sufficient reason-Leibniz concludes that the divisibility of objects does not stop at any level. This conclusion is, of course, incompatible with the existence of atoms. The reasoning above shows that if we suppose that atomism is true and that God created the best possible world, then there is a reason why the divisibility of objects at our worlds should stop at a certain level-since we have a reason to locate the atoms at some particular level. The bottom line is this. Further divisibility adds complexity to the world. God knows what the minimum complexity required to create the most perfect world is. Thus, God knows when to stop the divisibility of objects. Therefore, from all of the above, God has a reason to create atoms.

Manuscrito - Rev. Int. Fil. Campinas, v. 40, n. 2, pp. 19-38, abr.-jun. 2017. 
Of course, I do not take the previous arguments to have shown that atoms are indeed possible. This is so because I am not at all convinced that there is a God and that she created the best of all possible worlds. The previous argument only shows that there is an internal tension in Leibniz's philosophy: he cannot both think that based on The Principle of Sufficient Reason we can conclude that there are no atoms and that God created the best of all possible worlds.

Now, let's take a critical look at Leibniz's second argument. Recall that the point of the argument was this: since there are no purely external denominations, two atoms could only be distinguished by their size and form, given that they are perfectly homogeneous. Then Leibniz notes that from this it follows that there cannot be two atoms of the same size and form, given the principle of identity of indiscernibles. This is something he finds absurd. I do not think it is absurd, but that is not the point I want to make. The important point is this: if we accept that there are no purely extrinsic denominations, then we can run Leibniz's second argument against the existence of atoms to argue against the existence of pretty much any object. Thus, the argument overgeneralizes in a bad way.

Here is how the argument goes. Take two non-homogeneous objects and assume that they are internal duplicates. Thus, whatever internal difference one of them has, the other has as well-for example, if one has a red dot on its left side, the other has an indistinguishable red dot on exactly the same spot. Given that there are no purely external denominations, these two objects can only be differentiated by their internal features. But they are exactly alike internally. Thus, we reach the conclusion that there can only be an object of this kind, and not two. Leibniz should find this conclusion absurd as well, but he wouldn't want to deny that there can be non-homogeneous objects. Thus, it seems that Leibniz's second argument against the existence of atoms overgeneralizes in an undesirable way.

\section{Concluding remarks}

What lessons can we draw from Leibniz's arguments? Can we, as

Manuscrito - Rev. Int. Fil. Campinas, v. 40, n. 2, pp. 19-38, abr.jun. 2017. 
contemporary metaphysicians, extract some insights from them? I believe we can, specially from the first argument.13 Notice that we criticised Leibniz's first argument on the ground that it cannot hold along with the claim that God created the best of possible worlds. Really what we showed is only that Leibniz is not entitled to that argument. However, it is reasonable to think that most contemporary metaphysicians do not believe, with good reason, that God created the best possible world: perhaps it is safe to assume that most of them don't believe in the existence of God to begin with. Hence, if we are to challenge Leibniz's first argument we have to do it on different grounds. To defend first that God created the best possible world in order to wield that claim against Leibniz doesn't strike me as a good strategy.

We need to find a possible reason why the divisibility of objects should stop at some point, without invoking anything like God's wisdom. I am not sure what to say here--clearly Leibniz argument is fighting back. Perhaps we could say something like this: well, maybe the world is made of such-and-such fundamental physical particles, and it could very well be that those particles are indivisible---that is the point where divisibility in fact stops. But, why is the physical stuff in this world indivisible at that point? Let's say we did some empirical research and found it to be that way: that is the kind of material this world is made of.

A reply like this would leave Leibniz quite dissatisfied. We need to give him a reason why the world is made of that physical stuff, rather than other physical stuff that is indivisible at some other particular point. I do not know we can provide such a reason. Physicists have enough trouble trying to figure out what the fundamental physical particles are. To figure out why the world is made of that stuff rather than some other stuff seems to be extremely difficult.

At present this is the best I can do to put pressure on Leibniz's first argument: we can turn The Principle of Sufficient Reason against it. Suppose we cannot find a reason why the world is made of stuff that

\footnotetext{
13 The second argument is not as interesting from a contemporary perspective. That argument relies on the claim that all truths are identity statements and that there are no extrinsic denominations. To the best of my knowledge no one holds to those views anymore.
}

Manuscrito - Rev. Int. Fil. Campinas, v. 40, n. 2, pp. 19-38, abr.-jun. 2017. 
stops dividing at some point rather than at another. Leibniz would like to conclude from this that the stuff the world is made of is infinitely divisible. But we could ask, why is the world made of that infinitely divisible stuff rather than from stuff that is not infinitely divisible?

Let's bring God back into the picture, but this time only to make our argument more colorful: as such, God is a perfectly dispensable part of the argument. Suppose God is about to create the world, and she is at the point where she has to select the materials she's going to use. She could use the physical stuff that stops dividing at point $\mathrm{x}$, or the one that stops dividing at point $y$, or the one that stops dividing at point $z, \ldots$,or the one that is infinitely divisible. Leibniz would like to convince us that it would be an arbitrary choice to pick any of the stuff that stops dividing at some point, and then the only option left is the stuff that is infinitely divisible. But is this correct? Why is picking the stuff that is infinitely divisible less arbitrary than picking any of the others? As a matter of physical architecture it is safe to assume that we could build a world with any of those materials--the problem never was that if the world were made of atoms it would crumble. We cannot provide a reason why any of the stuff that is not infinitely divisible should be selected, but I don't think we can provide a reason for selecting the stuff that is infinitely divisible. If any of the materials will do, picking the one that divides at point $\mathrm{x}$ seems as arbitrary as picking the one that is infinitely divisible.

It seems that we just hit a wall--picking atoms doesn't seem to satisfy The Principle of Sufficient Reason, but picking an infinitely divisible material doesn't do it either. An option could be to abandon The Principle of Sufficient Reason. This would open new doors. For instance, we could say that maybe the world is made of stuff that is not infinitely divisible, and that there is no reason for this. We could also say that maybe the world is made of stuff that is infinitely divisible, and that there is no reason for this. Another option could be to stick to the principle and recognize that when it comes to matters of fundamental metaphysics, we can't always provide reasons for every substantial claim, even if, in principle, they are available. For what is worth, I think that contemporary metaphysicians should pick that option. In fact I think many have, but that is a question that I cannot pursue here.

Manuscrito - Rev. Int. Fil. Campinas, v. 40, n. 2, pp. 19-38, abr.jun. 2017. 


\section{References}

COVEr, J.A. \& HAWTHORne J. Substance and Individuation in Leibnir, Cambridge, 1999.

GARBER, D. "Leibniz: physics and philosophy", in The Cambridge Companion to Leibiniz, Cambrige, 1995.

LeIBNIZ, G. W. "Primary Truths", in Philosophical Papers, (trans. R. Ariew and D. Garber), Hackett, 1989.

"Discourse on Metaphysicas", in Philosophical Papers, (trans. R. Ariew and D. Garber), Hackett, 1989.

"The Principles of Philosophy, or, the Mondology", in Philosophical Papers, (trans. R. Ariew and D. Garber), Hackett, 1989. "Leibniz's Fifth Paper", in Philosophical Papers, (trans. R. Ariew and D. Garber), Hackett, 1989.

"Leibniz to Volder 20 June 1703", in Philosophical Papers, (trans. R. Ariew and D. Garber), Hackett, 1989.

"Leibniz Fourth Letter to Clarke", in Philosophical Papers, (trans. R. Ariew and D. Garber), Hackett, 1989.

"Leibniz Third Paper to Clarke", in Pbilosopbical Papers, (trans. R. Ariew and D. Garber), Hackett, 1989.

New Essays on Human Understanding, Cambridge, 2003.

MCDANIEL, K. "Extended simples.” Philosophical Studies, 133(1), 131-141, 2007.

SCHAFFER, J. "Is there a Fundamental Level?", Nous 37:3 498-517, 2003.

"Monism: the priority of the whole". Philosophical Review, 119(1), 31-76, 2010.

Russell, B. Critical Exposition of the Philosophy of Leibniæ, John Dickens \& Northampton, 1971.

Manuscrito - Rev. Int. Fil. Campinas, v. 40, n. 2, pp. 19-38, abr.jun. 2017. 